\title{
Implication of osteoplastic flap for frontal sinus surgery in the endoscopic era
}

\section{Aishwarya Raj Pillai Devaraj*, Kothegala Chandrashekariah Prasad, Abhilasha Karunasagar, Manna Jose Pappanacherry, Harshitha Naganna Gowda, Sreelekshmi Sukumaran Nair, Brindha Hennur Subramani}

Department of Otorhinolaryngology Head and Neck Surgery, Sri Devaraj Urs Medical College, Tamaka, Kolar, Karnataka, India

Received: 01 August 2019

Revised: 05 October 2019

Accepted: 14 October 2019

\section{*Correspondence:}

Dr. Aishwarya Raj Pillai Devaraj,

E-mail: ash.raj21@gmail.com

Copyright: (C) the author(s), publisher and licensee Medip Academy. This is an open-access article distributed under the terms of the Creative Commons Attribution Non-Commercial License, which permits unrestricted non-commercial use, distribution, and reproduction in any medium, provided the original work is properly cited.

\section{ABSTRACT}

In the present era where functional endoscopic sinus surgery is the mainstay of management for any frontal sinus disease, we present a case series comprising six cases of various frontal sinus pathology that were managed with an external approach using a bicoronal osteoplastic flap technique of which three cases were of inverted papilloma, one case of allergic fungal rhinosinusitis, one case of frontal mucocele and a case of road traffic accident with frontal bone and nasal bone fracture. The cases had a mean follow-up period of 6 months. There was no recurrence of disease and no significant postoperative complications have been reported during the follow-up period so far. Osteoplastic anterior wall approach to the frontal sinus has proved to be one of the most effective, simple, and reliable procedures with excellent success rate and good cosmesis.

Keywords: Frontal sinus disease, Osteoplastic frontal sinus flap, Endoscopic sinus surgery

\section{INTRODUCTION}

The management of frontal sinus disorders is a matter of debate due to its variable anatomy and proximity to critical structures such as the orbit and the anterior skull base and hence frontal sinus surgery is different from the relatively more straightforward surgical approaches to the rest of the paranasal sinuses. Endoscopic approach to diseases of the paranasal sinuses is more popular and the preferred technique in the current era. However, with this approach it is difficult to address pathology in certain areas especially the lateral most aspect of the frontal sinus and the supraorbital cells, which are most commonly involved in extensive disease. Hence in such scenarios an open approach is ideal for complete eradication of the disease whereby recurrences are less.
Recent advances in imaging and endoscopic techniques have led to an evolutionary progress in intranasal endoscopic procedures for frontal sinus lesions. However, certain frontal sinus /diseases such as frontal/frontoethmoidal osteoma, tumours causing posterior table erosion, laterally placed disease extensively involving supraorbital cells and absent or distorted intranasal landmarks result in failure of endoscopic clearance. ${ }^{1}$ In such challenging situations open approach is still a valuable modality.

A case series comprising six cases of varied frontal sinus pathology that were managed with an external approach using a bicoronal osteoplastic flap technique are included in this study. The study was carried out in the Department of Otorhinolaryngology, head and neck surgery Sri Devaraj Urs Medical College, a tertiary care centre in Tamaka, Kolar. 
With this study our aim is to discuss the outcome of our experience with external frontal sinus osteoplastic flap approach in terms of intraoperative disease clearance for extensive frontal sinus lesions beyond the scope of endoscopic excision.

\section{CASE REPORT}

The study period was from January 2015 to December 2018. A total of six cases with varied pathology having extensive disease have been included in this study of which three were inverted papilloma, one case of allergic fungal rhinosinusitis, one case of frontal mucocele and a case of road traffic accident with frontal bone and nasal bone fracture. Of these, two were revision cases who had undergone excision previously for inverted papilloma and the other for frontal mucocele (Table 1).

In all the cases CT scan showed extensive pneumatisation of frontal sinus up to the level of lateral orbital margin with supraorbital cells pneumatisation up to the lateral orbital wall.

Table 1: List of cases included in the study.

\begin{tabular}{|c|c|c|c|c|c|}
\hline Case & Age (yrs) & Sex & CT finding & Diagnosis & Treatment modality \\
\hline 1 & 48 & Male & $\begin{array}{l}\text { Opacified frontal ethmoidal and } \\
\text { maxillary sinus; extension of the } \\
\text { disease up to the lateral orbital wall } \\
\text { and involvement of supraorbital cells }\end{array}$ & Inverted papilloma & Osteoplastic flap \\
\hline 2 & 54 & Male & $\begin{array}{l}\text { Opacified frontal ethmoidal and } \\
\text { maxillary sinus; extensive frontal ostia } \\
\text { cicatrisation with prominent frontal } \\
\text { ostia beak }\end{array}$ & $\begin{array}{l}\text { Inverted papilloma } \\
\text { Revision case }\end{array}$ & Osteoplastic flap \\
\hline 3 & 42 & Male & $\begin{array}{l}\text { Opacified frontal ethmoidal and } \\
\text { maxillary sinus; extensive disease up } \\
\text { to the lateral orbital wall with } \\
\text { involvement of the supraorbital cells }\end{array}$ & Inverted papilloma & Osteoplastic flap \\
\hline 4 & 24 & Male & $\begin{array}{l}\text { Mucocele of the frontal sinus pushing } \\
\text { the orbit inferiorly; Extensive frontal } \\
\text { ostia cicatrisation with prominent } \\
\text { frontal ostia beak }\end{array}$ & $\begin{array}{l}\text { Mucocele revision } \\
\text { case }\end{array}$ & $\begin{array}{l}\text { Endoscopic Lothrop } \\
\text { converted to external } \\
\text { osteoplastic flap }\end{array}$ \\
\hline 5 & 40 & Male & $\begin{array}{l}\text { Opacification of the frontal ethmoidal } \\
\text { and maxillary sinus; involvement of } \\
\text { the supraorbital cells }\end{array}$ & $\begin{array}{l}\text { Allergic fungal } \\
\text { rhinosinusitis }\end{array}$ & Osteoplastic flap \\
\hline 6 & 26 & Male & $\begin{array}{l}\text { Fracture of the anterior table of frontal } \\
\text { sinus; undisplaced fracture of the } \\
\text { nasal bone }\end{array}$ & $\begin{array}{l}\text { Road traffic accident } \\
\text { with frontal and nasal } \\
\text { bone fracture }\end{array}$ & Osteoplastic flap \\
\hline
\end{tabular}

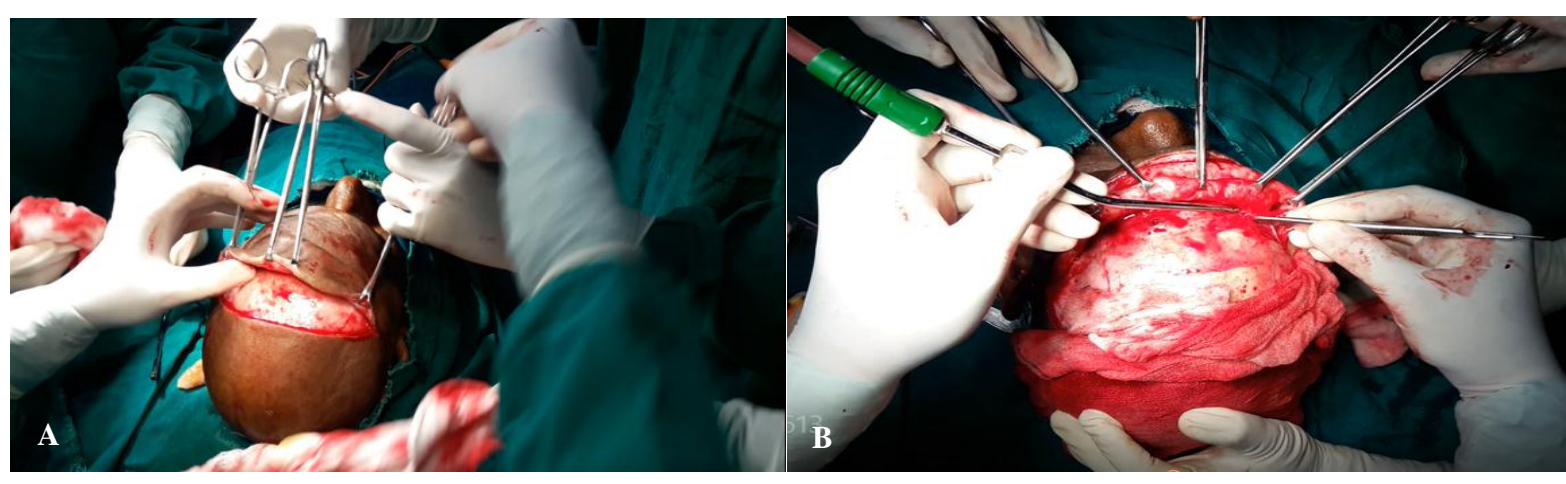

Figure 1 (A and B): The osteoplastic flaps were raised using bicoronal incision and dissected till the galea, with elevation of the frontalis muscle.

The osteoplastic flaps were raised using bicoronal incision and dissected till the galea, with elevation of the frontalis muscle (Figure 1A and B). The scalp flap was pulled caudally on both sides, leaving behind the periosteum and the bone, thus preserving the supraorbital and supratrochlear vascular bundle. A template of the frontal sinus obtained from the occipitofrontal plain radiograph, preserved in a disinfectant solution was positioned on the root of the nose and borders of the frontal sinus were estimated (Figure 2A and B). The pericranium was incised and elevated using blunt as well as sharp dissection up to the supraorbital ridge and over the root of the nose slightly, being pedicled caudally at the bone. The anterior wall of the frontal sinus was 
elevated as inferiorly based bony flap after joining the burr holes drilled along the outline of the frontal sinus with an $\sim 30^{\circ}$ angulation directed toward the frontal sinus maintained to ensure a wide surface for the later replacement of the bony flap (Figure $3 \mathrm{~A}$ and $\mathrm{B}$ ).
The cases had a mean follow-up period of 6 months. There was no recurrence of disease and no significant postoperative complications have been reported during the follow-up period so far.

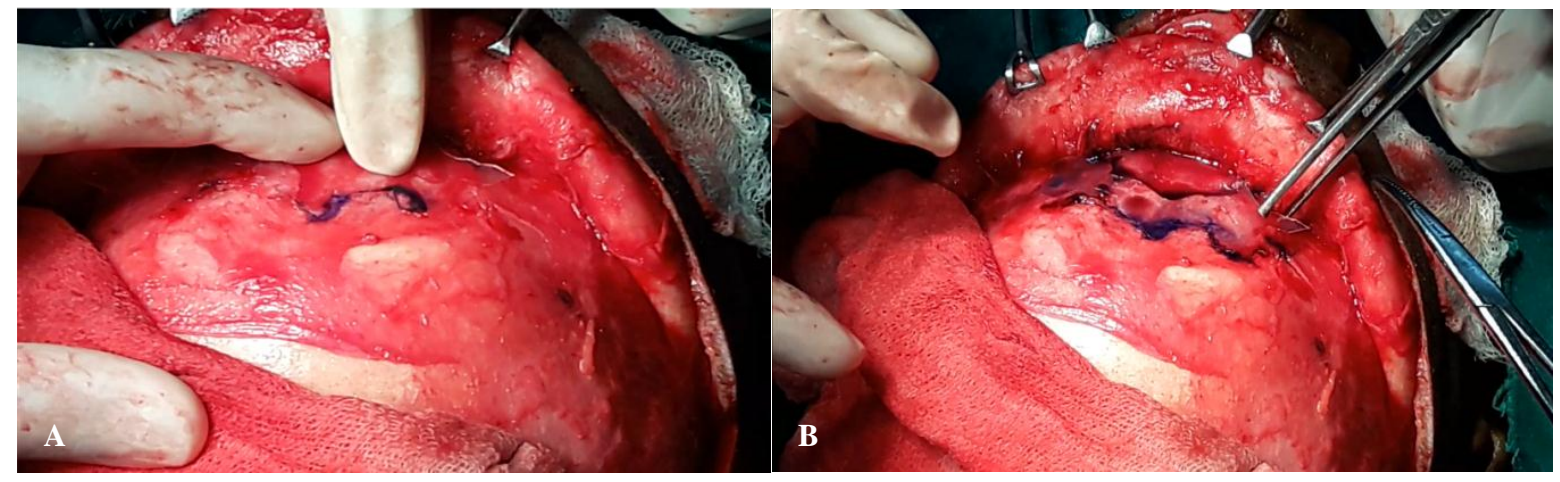

Figure 2 (A and B): A template of the frontal sinus obtained from the occipitofrontal plain radiograph.

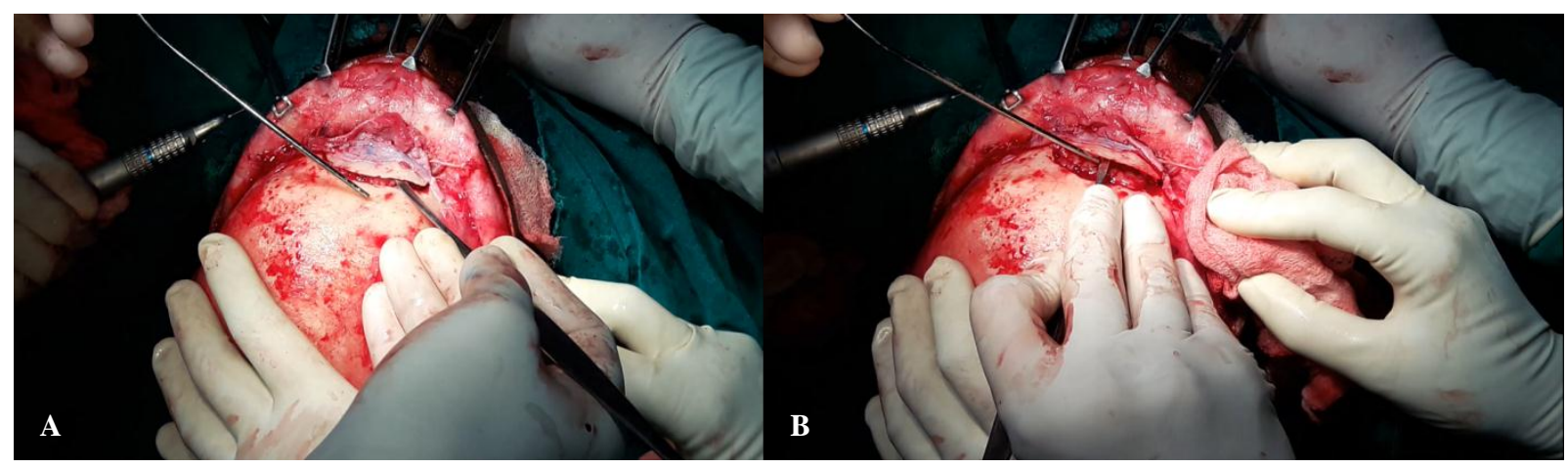

Figure 3 (A and B): Anterior wall of the frontal sinus was elevated as inferiorly based bony flap.

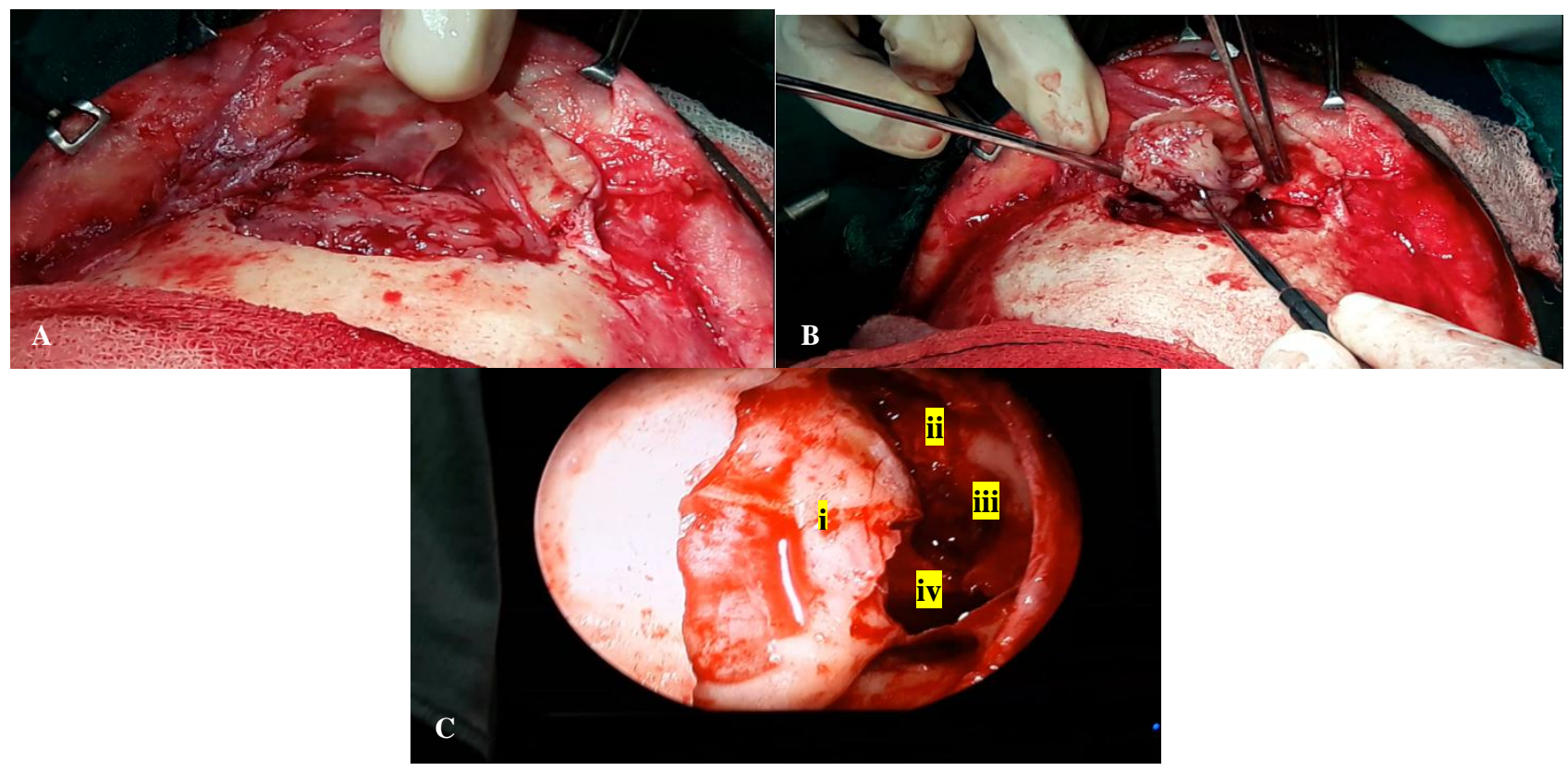

Figure 4: (A and B) Exposed frontal sinus showing extensive disease i.e., inverted papilloma involving the frontal going into the supraorbital cells, $(\mathrm{C})$ view of the frontal sinus with the endoscope after clearing the disease: i) exposed dura, ii) septum, iii) orbit and iv) supraorbital cells. 


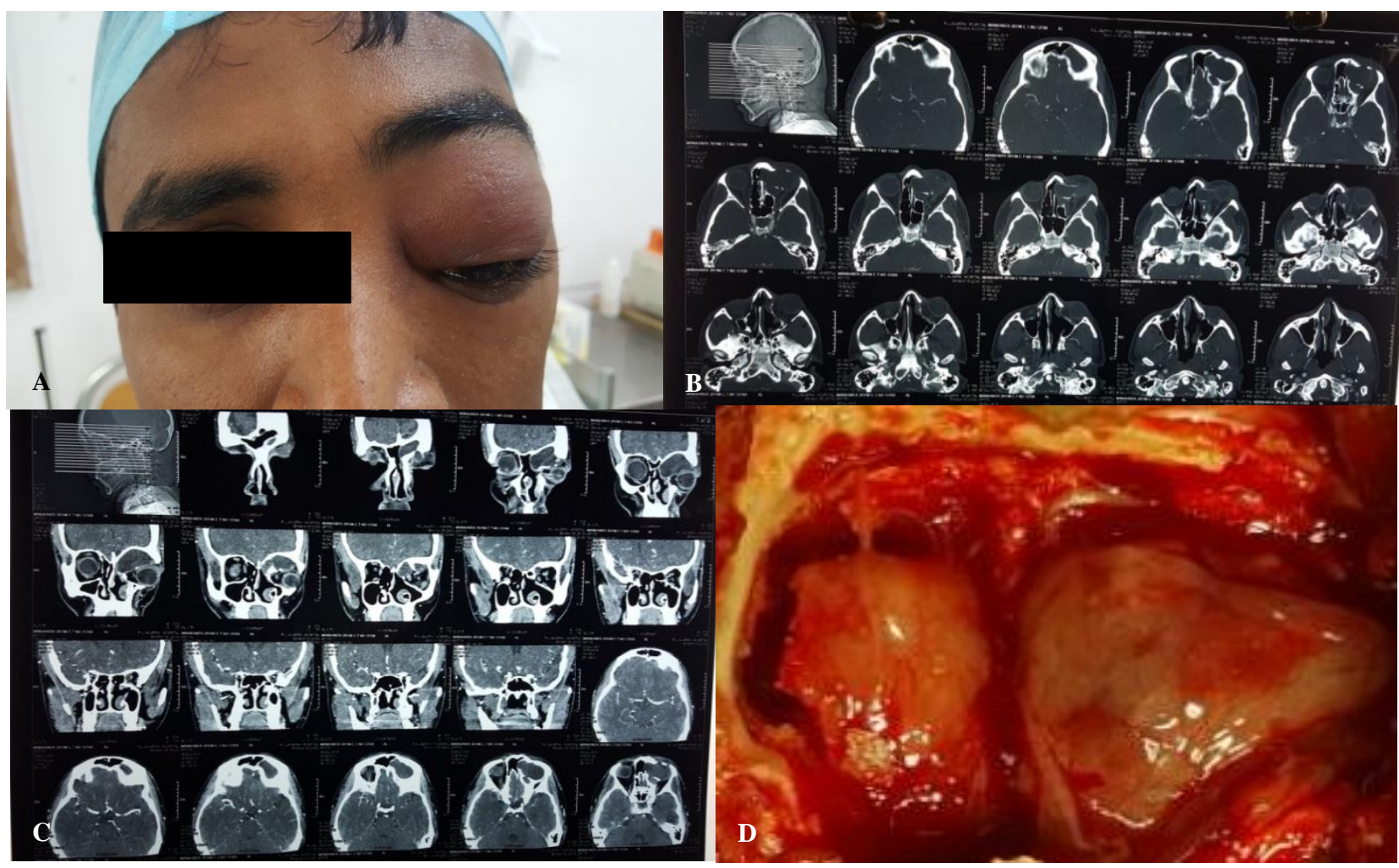

Figure 5: (A) Patient with frontal sinus mucocele presenting with supraorbital swelling, (B and C) CT scans of the patient with frontal mucocele, extensive cicatrisation of the frontal ostia beak, (D) intraoperative, the frontal mucocele.

\section{DISCUSSION}

The various surgical approaches to deal with frontal sinus disorders can be either external, intranasal, or combined depending on the type and extent of disease. ${ }^{2}$ The endoscopic approach to diseases of the paranasal sinuses is the more popular and preferred technique in the current era. However, with this approach it is difficult to address pathology in certain areas especially the lateral most aspect of the frontal sinus and the supraorbital cells, which are most commonly involved in extensive disease. Hence in such scenarios an open approach is ideal for complete eradication of the disease whereby recurrences are less. The main objective of this study was to study the outcome of external frontal sinus osteoplastic flap approach in terms of intraoperative disease clearance for extensive frontal sinus lesions beyond the scope of endoscopic excision.

External approach accounts for about 5\% of all frontal sinus surgeries, with the osteoplastic flaps usually being reserved for those disorders that cannot be successfully treated endonasally. ${ }^{3-5}$ This approach provides an optimal view of the entire frontal sinus and allows complete microscopic removal of the disease and obliteration of frontal sinus if required. External approach includes frontal sinus trephination, frontoethmoidectomy (LynchHowarth) or osteoplastic bone flap. Intranasal approach using endoscope can be ranging from Messerklinger technique with special emphasis on mucosal preservation to more radical endoscopic approaches such as the modified Lothrop (frontal sinus drill out) and balloon sinuplasty. ${ }^{6-8}$ Such wide variety of treatment modalities makes the optimal management protocol for frontal sinus disorders a matter of conflict and debate. There is no single approach that has been able to fulfil the criteria for the modality of choice in terms of excellent results, no recurrence or residual disease, minimal morbidity, short hospital stay, uneventful long-term postoperative course, and good cosmesis in cases of extensive disease involvement.

In 1884, Ogston described trephination through the anterior table to evacuate the frontal sinus and placed a tube in the nasofrontal duct. ${ }^{9}$ However, this technique had high failure rate due to frontonasal duct stenosis. ${ }^{10}$ Riedel's procedure in which the anterior table was removed to clear disease was marred by postoperative cosmetic forehead deformity and thus abandoned. In 1908, Knapp performed an extensive ethmoidectomy through the medial orbital wall, leaving the anterior wall of the frontal sinus intact but removing the diseased mucosa and enlarging the frontonasal duct. ${ }^{11}$ Lothrop, resected the frontal sinus floor between the frontal recess and the intersinus septum along with the upper aspect of the nasal septum after an ethmoidectomy using an external approach. ${ }^{12}$ Lynch and Howarth, entered the frontal sinus through an external approach through the medial orbital wall. ${ }^{13,14}$ The osteoplastic bone flap procedure was described by Tato and Bergaglio, which 
permitted an optimal view of the frontal sinus allowing complete removal of the mucosa, followed by obliteration of the sinus with abdominal fat with no cosmetic deformity. ${ }^{15,16}$ Goodale and Montgomery claimed excellent success rates with uneventful postoperative recovery using osteoplastic flaps for various indications in their case series reported in 1958 and $1976 .{ }^{17}$ The procedure gained popularity and became the standard procedure during that period.

In our case series of different pathologies involving the frontal sinus, given the nature of the disease the use of an endoscope was not feasible and hence the osteoplastic flap technique was resorted to as the procedure of choice. For the inverted papilloma cases modified WeberFerguson incision was made for proper exposure and best possible access; but the disease clearance from the frontal sinus was possible due to the exposure of the frontal sinus using the osteoplastic flap (Figure 4 (A-C)). The frontal mucocele case a revision case presented with swelling in the supraorbital region was initially planned for Lothrop approach but in view of extensive cicatrisation of the frontal ostia beak the surgery was converted to external osteoplastic frontal sinus flap which helped in easier access to the frontal sinus for disease clearance (Figure 5 (A-D)). In case of comminuted fracture of the anterior table, the osteoplastic flap technique helped in wide exposure of the area of defect so that it could be repaired by means of plate screw fixation following obliteration of the sinus.

Depending on the extent of disease it has now become possible to open the frontal recess with mucosal preservation with the advent of computed tomography scans, navigation system and endoscopes. ${ }^{18}$ Nowadays many surgeons use the combined approach that is both the endoscopic and external approaches to address the frontal sinus. The review and analysis of various studies has shown that only the osteoplastic flap has better results as compared with endoscopic approaches in terms of reducing recurrence and need for revision procedures, and therefore remains the gold-standard technique. ${ }^{19}$

\section{CONCLUSION}

In the present era even though there is more emphasis to endoscopic approaches, osteoplastic frontal sinus flap is still one of the most relevant external approaches to frontal sinus even today especially for laterally placed frontal sinus pathology, narrow anteroposterior diameter of the sinus, posterior table fractures or anterior table fractures with deformity, neo-osteogenesis of the frontal recess and frontal ostia. Hence osteoplastic flap approach still needs to be part of the teaching curriculum keeping in mind its cost effectiveness, with minimal need for specialized infrastructure and the relative ease for beginners. Osteoplastic flap is thus here to stay until the time endoscopic setup and navigation system is widespread in every level of healthcare delivery system.
Funding: No funding sources Conflict of interest: None declared

Ethical approval: Not required

\section{REFERENCES}

1. Jones NS. Management of frontal sinuses. In: Flint PW, Haughey BH, Lund VJ, Niparko JK, Richardson MA (eds). Cummings otolaryngology head and neck surgery. 5th edition. Philadelphia, PA: Elsevier; 2010: 781-784.

2. Conger BT, Illing E, Bush B, Woodworth BA. Management of Lateral Frontal Sinus Pathology in the Endoscopic Era . SAGE J. 2014:159-63.

3. Bockmuhl U, Kountakis SE, Senior BA. Wolfgang Draf osteoplastic frontal sinusotomy and reconstruction of frontal defects. In: Kountakis SE, Senior A, Draf W, editors. Frontal sinus stilianos, thieme. New York: Springer; 2005: 281-290.

4. Weber R, Draf W, Kahle G, Kind M. Obliteration of the frontal sinus - state of the art and reflections on new materials. Rhinol. 1999;37:1-15.

5. Weber R, Draf W, Keerl R, Kahle G, Schinzel S, Thomann S, Lawson W. Osteoplastic frontal sinus surgery with fat obliteration: technique and longterm results using magnetic resonance imaging in 82 operations. Laryngoscope. 2000;110:1037-44.

6. Rajapaksa SP, Ananda A, Cain T, Oates L, Wormald PJ. The effect of the modified endoscopic Lothrop procedure on the mucociliary clearance of the frontal sinus in an animal model. Am J Rhinol. 2004;18:183-7.

7. Wormald PJ, Ananda A, Nair S. The modified endoscopic Lothrop procedure in the treatment of complicated chronic frontal sinusitis. Clin Otolaryngol Allied Sci. 2003;28:215-20.

8. Kim E, Cutler JL. Balloon dilatation of the paranasal sinuses: a tool in sinus surgery. Otolaryngol Clin North Am. 2009;42:847-56.

9. Ogston A. Trephining the frontal sinus for catarrhal diseases. Men Chron Manchester. 1884;1:235

10. Coakley CG. Frontal sinusitis: diagnosis, treatment, and results. Trans Am Laryngol Rhinol Otol Soc. 1905;11:101.

11. Knapp A. The surgical treatment of orbital complications in disease of the nasal accessory sinuses. JAMA. 1908;51:299.

12. Lothrop HA. XIV. Frontal sinus suppuration: the establishment of permanent nasal drainage; the closure of external fistulae; epidermization of sinus. Ann Surg. 1914;59:937-57.

13. Lynch RC. The technique of a radical frontal sinus operation which has given me the best results. Laryngoscope. 1921;31:1.

14. Howarth WG. Operations on the frontal sinus. J Laryngol Otol. 1921;36:417-21.

15. Tato JM, Bergaglio OE. Cirurgia del frontal injerto de grosa. Nueva tecnica. Laryngoscope. 1954;64:504-21. 
16. Goodale RL, Montgomery WW. Experience with osteoplastic anterior wall approach to the frontal sinus. Arch Otolaryngol. 1958;68:271.

17. Hardy JM, Montgomery WW. Osteoplastic frontal sinusotomy: an analysis of 250 operations. Ann Otol Rhinol Laryngol. 1976;85(Pt 1):523-32.

18. Volpi L, Pistochini A, Bignami M, Meloni F, Turri Zanoni M, Castelnuovo P. A novel technique for tailoring frontal osteoplastic flaps using the ENT magnetic navigation system. Acta Otolaryngol. 2012;132:645-50.
19. Ulualp SO, Carlson TK, Toohill RJ. Osteoplastic flap versus modified endoscopic Lothrop procedure in patients with frontal sinus disease. Am J Rhinol. 2000;14:21-6.

Cite this article as: Devaraj ARP, Prasad KC,

Karunasagar A, Pappanacherry MJ, Gowda HN, Nair SS,

Subramani BH. Implication of osteoplastic flap for frontal sinus surgery in the endoscopic era. Int $\mathrm{J}$

Otorhinolaryngol Head Neck Surg 2019;5:1717-22. 